\title{
Effect of the His Residue on the Cyclization of $b$ Ions
}

\author{
Benjamin J. Bythell, ${ }^{\text {a }}$ Michaela Knapp-Mohammady, ${ }^{\text {b }}$ Béla Paizs, ${ }^{\text {a }}$ and \\ Alex G. Harrison ${ }^{c}$ \\ a Computational Proteomics Group, German Cancer Research Center (DKFZ), Heidelberg, Germany \\ ${ }^{\mathrm{b}}$ Division of Functional Genome Analysis, German Cancer Research Center (DKFZ), Heidelberg, Germany \\ ${ }^{\mathrm{c}}$ Department of Chemistry, University of Toronto, Toronto, Canada
}

The $\mathrm{MS}^{n}$ spectra of the $[\mathrm{M}+\mathrm{H}]^{+}$and $b_{5}$ peaks derived from the peptides HAAAAA, AHAAAA, AAHAAA, AAAHAA, and AAAAHA have been measured, as have the spectra of the $b_{4}$ ions derived from the first four peptides. The $\mathrm{MS}^{2}$ spectra of the $[\mathrm{M}+\mathrm{H}]^{+}$ions show a substantial series of $b_{n}$ ions with enhanced cleavage at the amide bond C-terminal to His and substantial cleavage at the amide bond $\mathrm{N}$-terminal to His (when there are at least two residues $\mathrm{N}$-terminal to the His residue). There is compelling experimental and theoretical evidence for formation of nondirect sequence ions via cyclization/reopening chemistry in the CID spectra of the $b$ ions when the His residue is near the C-terminus. The experimental evidence is less clear for ions when the His residue is near the N-terminus, although this may be due to the use of multiple alanine residues in the peptide making identifying scrambled peaks more difficult. The product ion mass spectra of the $b_{4}$ and $b_{5}$ ions from these isomeric peptides with cyclically permuted amino acid sequences are similar, but also show clear differences. This indicates less active cyclization/reopening followed by fragmentation of common structures for $b_{n}$ ions containing His than for sequences of solely aliphatic residues. Despite more energetically favorable cyclization barriers for the $b_{5}$ structures, the $b_{4}$ ions experimental data show more clear evidence of cyclization and sequence scrambling before fragmentation. For both $b_{4}$ and $b_{5}$ the energetically most favored structure is a macrocyclic isomer protonated at the His side chain. (J Am Soc Mass Spectrom 2010, 21, 1352-1363) (C 2010 American Society for Mass Spectrometry

$\mathrm{P}$ rotonated or multiply-protonated peptides are routinely sequenced by tandem mass spectrometry (MS/MS) [1-3] techniques. Under the predominantly-used, low-energy collisional activation conditions, protonated peptides usually fragment at amide bonds. In the ideal case, such fragmentation [4] only leads to series of direct $b$ and / or $y$ ions $[5,6]$ which contain the $\mathrm{N}$ - and C-terminus, respectively. It is these series of direct $b$ and $y$ ions, which are primarily utilized in bioinformatics algorithms to deduce the sequence information. The generation of nondirect sequence ions $[7,8]$ may lead to uncertainty in the interpretation of the observed product ion mass spectra. The presence of such ions violates one of the basic assumptions on which most current sequencing algorithms are based; that the primary sequence of the protonated peptide does not change during the MS/MS process.

While it is known $[9,10]$ that $y$ ions are protonated amino acids $\left(y_{1}\right)$ or protonated, truncated peptides $\left(y_{n}\right.$ $n>1)$, the structures of the $b$ ions present a much more

Address reprint requests to Dr. A. G. Harrison, Department of Chemistry, University of Toronto, Toronto, ON M5S 3H6, Canada or Dr. B. Paizs, Computational Proteomics Group, German Cancer Research Center (DKFZ), Heidelberg, Germany. E-mail: aharriso@chem.utoronto.ca or b.paizs@dkfz-heidelberg.de complicated picture [11]. The acylium ion structure was originally proposed [6] for $b$ ions, but extensive studies [11-17] have presented strong evidence that cyclization at the C-terminus to form a protonated oxazolone structure has, in fact, occurred. Quite recently, infrared multiple photon dissociation (IRMPD) [18-22] and gasphase H/D exchange (HDX) studies [23] provided experimental evidence for the protonated oxazolone structure for small $b_{n}$ ions $(n=2-4)$. Conversely, when a strong nucleophile is present in the peptide, alternative side-chain cyclization reactions involving this nucleophile may also occur [4, 24-31].

Oxazolone ring terminated $b_{n}$ ions dissociate by degradation of their C-termini $[13,32]$ to form the corresponding $a_{n}$ ion and shorter $b_{i}(i<n)$ fragments because the oxazolone ring is more labile than backbone amide bonds (the 'oxazolone' rule [33]). While these pathways dominate for small $b_{n}$ ions, this is not the case for larger $b$ fragments where elimination of formally internal residues is often observed [7, 8, 33]. Early studies by Boyd and coworkers [34, 35] reported the formation of such nondirect sequence ions in the fragmentation of doubly-charged $b$ ions containing lysyl or ornithyl residues. Elimination of the formally internal residues was interpreted in terms of cyclization/reopening reactions before fragmentation. 
This rearrangement chemistry has recently been studied $[7,8,33]$ on YAGFL- $\mathrm{NH}_{2}$-related peptides, and protonated $\mathrm{G}_{5} \mathrm{R}$ using a variety of experimental and theoretical tools. Density functional calculations indicate $[7,8,33]$ that attack of the N-terminal amine group on the C-terminal oxazolone formed in the initial fragmentation process leads to formation of a macrocyclic $b_{n}$ isomer (Scheme $1, n \geq 4$ ). After proton transfer, this macrocyclic structure can open at a variety of positions to form a variety of oxazolones resulting in scrambling of the original amino acid sequence. All oxazolone $b_{n}$ isomer ions can potentially fragment at the comparatively fragile C-terminal oxazolone group to form the next-lower $b_{n-1}$ ion ('oxazolone' rule [33]). Such fragmentation of rearranged $b_{n}$ ions leads to nondirect sequence ions, thus explaining the elimination of formally internal residues. This 'scrambling' chemistry has the potential to result in confusion when attempting to sequence an unknown peptide. In the worst case scenario, 'scrambling' pathways are so prevalent that they lead to complete loss of direct sequence information upon CID [8].

In recent years, several groups [7, 8, 32, 33, 36-42] have studied the $b_{n}$ ion cyclization/reopening chemistry and $b_{n}$ ion structure. As would be expected, acetylation at the $\mathrm{N}$-terminus eliminates this cyclization process $[38,40]$ by preventing the $\mathrm{N}$-terminus acting as the oxazolone-attacking nucleophile which initiates cyclization. Elimination of formally internal residues was observed for a variety of $b$ ions ranging from $b_{4}$ to $b_{9}[7$, $8,37-41]$. Very recent IRMPD and theoretical studies [33] have demonstrated that the macrocyclic structure of $b_{5}$ formed from protonated $\mathrm{G}_{5} \mathrm{R}$ is a stable species
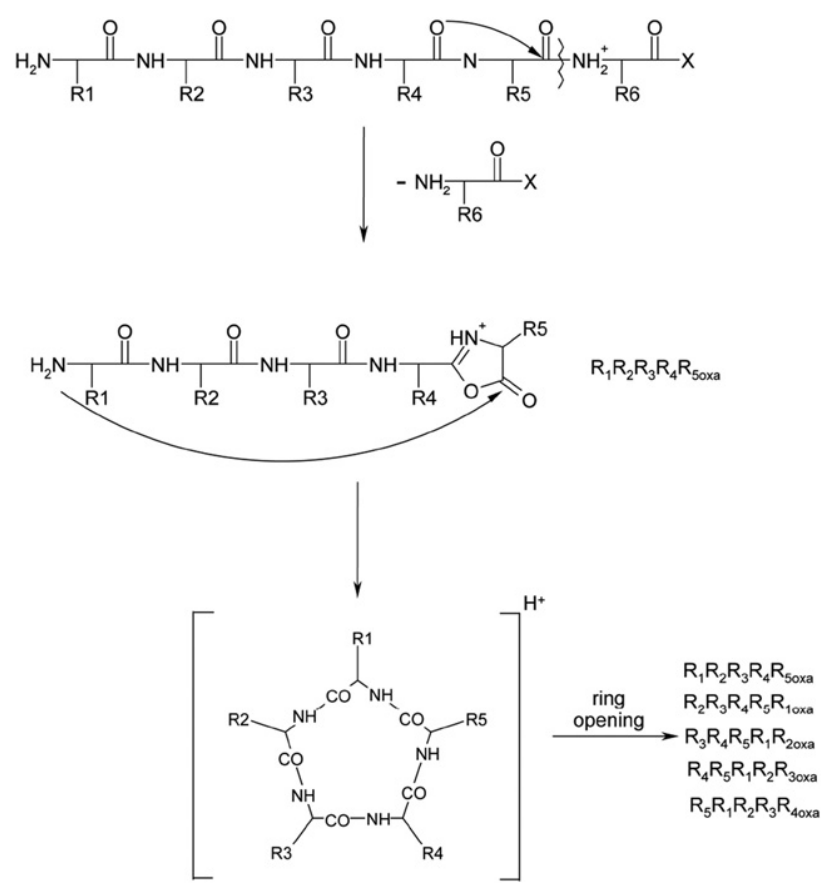

Scheme 1. Formation and cyclization/reopening chemistry of oxazolone-terminated $b_{5}$ ions. and not a transient intermediate. In fact, this study showed no evidence of the presence of the oxazolone form. The existence of the macrocyclic structure means formation of a 15-membered ring that is clearly unexpected based on entropic considerations [33, 41].

The cyclization and scrambling chemistries of $b_{n}$ ions were efficiently probed by studying the fragmentation of $b$ ions derived from peptides with systematically varied (cyclically permuted) amino acid sequences [8, 38,39 ]. In the following we will refer to this approach as the 'isomeric peptide' method. For example, the cyclization and scrambling pathways of $b_{5}$ ions composed of four Ala and a single Tyr residues were probed [38] by CID of the $b_{5}$ ions from protonated YAAAAA, AYAAAA, AAYAAA, AAAYAA, and AAAAYA. The corresponding $b_{5}$ ions (nominally $\mathrm{YAAAA}_{\text {oxa }}, \mathrm{AYAAA}_{\text {oxa }}$ AAYAA $_{\text {oxa }}$ AAAYA $_{\text {oxa }}$ and AAAAY oxa ) produced nearly identical product ion spectra which showed abundant loss of the Ala and Tyr residues and contained numerous nondirect sequence ions. These experiments provided solid, but indirect evidence for the formation of macrocyclic structures (Scheme 1) in the fragmentation process. A key characteristics of the 'isomeric peptide' method is that the cyclization of $b_{n}$ ions is monitored by observing scrambled, nondirect sequence ions in similar spectra obtained for $b_{n}$ ions with nominally different sequences. This is also a limitation of the method because cyclization can still occur even though scrambling is not apparent from the investigated spectra especially if the investigated peptides contain the same residue repeatedly and opening of the macro-ring is preferred at this residue. In other words, the 'isomeric peptide' method is useful to demonstrate if cyclization to a common macrocyclic isomer is complete but is less efficient if competition of cyclization and direct fragmentation is pronounced. Another limitation is if elimination of one of constituting amino acid residues is suppressed, in these cases the corresponding nondirect sequence ions are not observed. The 'isomeric peptide' method has been successfully used to study $b_{5}$ ions with the YAGFL [8] and $b_{9}$ ions with the $\mathrm{YA}_{8}$ amino acid compositions.

Most of the previous studies of $b$ ion sequence scrambling have involved peptides containing relatively neutral amino acid residues. Consequently, the question largely remains as to whether such cyclization and sequence scrambling reactions also occur when strongly basic or acidic residues are present in the peptide. In the present study, we have examined the effect of the strongly basic histidine (His) residue on the full cyclization of $b_{n}$ ions and subsequent sequence scrambling using the experimental 'isomeric peptide' method and detailed density functional theory calculations on the macrocyclic and open $b_{n}$ structures and their isomerization reactions. The results indicate that cyclization and 'scrambling' does occur and, thus, is a potential problem for sequencing; however the degree of isomerization to a single structure before fragmentation is insufficient to make product ion mass 
spectra of all the isobaric $b_{n}$ ions identical as has been found in several earlier studies of peptides lacking basic residues $[8,38,41]$. More generally, the study provides insight into the fragmentation behavior of singlyprotonated peptides containing the His residue.

\section{Experimental}

All experimental work was carried out using an electrospray/quadrupole/time-of-flight (QqTOF) mass spectrometer (QStarXL; SCIEX, Concord, Canada). $\mathrm{MS}^{2}$ experiments were carried out in the usual fashion for $[\mathrm{M}+\mathrm{H}]^{+}$ions by mass-selecting the ions of interest with the mass analyzer $\mathrm{Q}$ with fragmentation in the quadrupole collision cell $\mathrm{q}$ and mass analysis of the ionic products with the time-of-flight analyzer. For the study of $b$ fragment ions, CID in the interface region produced fragment ions with those of interest being selected by the quadrupole mass analyzer $Q$ for fragmentation and analysis in the usual manner. By varying the collision energy in the collision cell $\mathrm{q}$ breakdown graphs expressing, in a qualitative fashion, the energy dependence of the fragmentation reactions were obtained.

Ionization was by electrospray with the sample, dissolved at micromolar levels in 1:1 $\mathrm{CH}_{3} \mathrm{OH}: 1 \%$ aqueous formic acid, introduced into the ion source at a flow rate of $10 \mu \mathrm{L} \mathrm{min}^{-1}$. Nitrogen was used as nebulizing and drying gas and as collision gas in the quadrupole collision cell. The peptides used (HAAAAA, AHAAAA, AAHAAA, AAAHAA, and AAAAHA) were obtained from Celtek Peptides (Nashville, TN, USA); they showed no impurities in their mass spectra and were used as received.

\section{Computational Details}

A conformational search engine [7, 8, 18, 19, 22, 43, 44] devised specifically to deal with protonated peptides and their fragments was used to scan the potential energy surfaces (PESs) of protonated cyclo-(HAAA) and cyclo-(HAAAA). For both cases, macrocyclic structures protonated at the His side chain and the backbone amide oxygens were characterized. For linear structures, protonation at the His side chain, C-terminal oxazolone ring, and N-terminal amino nitrogen were considered. All cyclic permutations of the HAAA and HAAAA sequences were considered: HAAA oxa $\mathrm{AHAA}_{\text {oxa }}, \mathrm{AAHA}_{\text {oxa }}, \mathrm{AAAH}_{\text {oxa }}$ for the $b_{4}$ fragment and HAAAA $_{\text {oxa }}$, AHAAA $_{\text {oxa }}$, AAHAA $_{\text {oxa }}$, AAAHA $_{\text {oxar }}$ and $\mathrm{AAAAH}_{\text {oxa }}$ for the $b_{5}$ fragment.

These calculations began with molecular dynamics (MD) simulations using simulated annealing on the above isomers and protonation sites using the Discover program (Biosym Technologies, San Diego, CA, USA), in conjunction with the AMBER force field [45] modified by us to allow amide nitrogen and oxygen protonated species. During the MD simulations, structures were regularly saved for further refinement by full geometry-optimization using the same force field. In the next stage of the process, these structures were analyzed by our own conformer-family search program. This program is able to group optimized structures into families based on the similarity of the most important characteristic torsion angles. The most stable species in these families were then fully optimized at the HF/3-21G, B3LYP/6-31G(d), and the B3LYP/6$31+\mathrm{G}(\mathrm{d}, \mathrm{p})$ levels.

Having scanned the PES, transition structures (TSs) corresponding to the various ring opening reactions of the macrocyclic $b_{4} b_{5}$ isomers were then sought at the B3LYP/6-31G(d) and B3LYP/6-31+G(d,p) levels of theory. The resulting TSs were checked using intrinsic reaction coordinate (IRC) calculations to unambiguously define which minima they connected. Relative energies were calculated by using the B3LYP/6$31+\mathrm{G}(\mathrm{d}, \mathrm{p})$ total energies and zero-point energy (ZPE) corrections determined at the B3LYP/6-31G(d) level. Total energies and ZPE-corrected relative energies are presented in Tables S1-S6 (Supporting Information, which can be found in the electronic version of this article). The Gaussian [46] suite of programs was used for all $\mathrm{ab}$ initio and DFT calculations.

\section{Results and Discussion}

\section{Fragmentation Reactions of $[\mathrm{M}+\mathrm{H}]^{+}$Ions of the Investigated Peptides}

The product ion mass spectra of the five $[\mathrm{M}+\mathrm{H}]^{+}$ions at $22 \mathrm{eV}$ collision energy are shown as stick spectra in Figure 1. In most cases, a series of $b$ ions is observed. For HAAAAA the most abundant $b_{n}$ ion is $b_{2}$ corresponding, nominally, to the HA $b_{2}$ ion. For the other compounds studied, the most abundant $b_{n}$ ion corresponds, nominally, to cleavage C-terminal to the His residue. Thus, AHAAAA shows $b_{2}$ as the most abundant fragment, AAHAAA shows $b_{3}$ as the most abundant fragment, AAAHAA shows $b_{4}$ as the most abundant fragment and AAAAHA shows $b_{5}$ as the most abundant $b$ fragment. This result is in agreement with an earlier report of enhanced cleavage at histidine [47]. It is worth noting that the spectra in Figure 1 display much fewer abundant nondirect sequence ions than have been observed for CID of protonated YAGFL- $\mathrm{NH}_{2}$ and related peptides $[7,8]$. Despite this reduction, at least one nondirect sequence ion is present for each precursor ion. The protonated AAAHAA and AAAAHA spectra show (at least) four and five nondirect sequence ions respectively. Additionally, it should be explicitly understood that the presence of multiple alanine residues in the analyzed peptides can 'hide' this type of process (if it occurs) in many cases due to the structural nondegeneracy of many $m / z$ values.

In addition, if there are at least two residues $\mathrm{N}$ terminal to His, one observes cleavage of the amide bond N-terminal to His resulting in formation of the appropriate $y$ ion. While $y$ fragments are observed only 

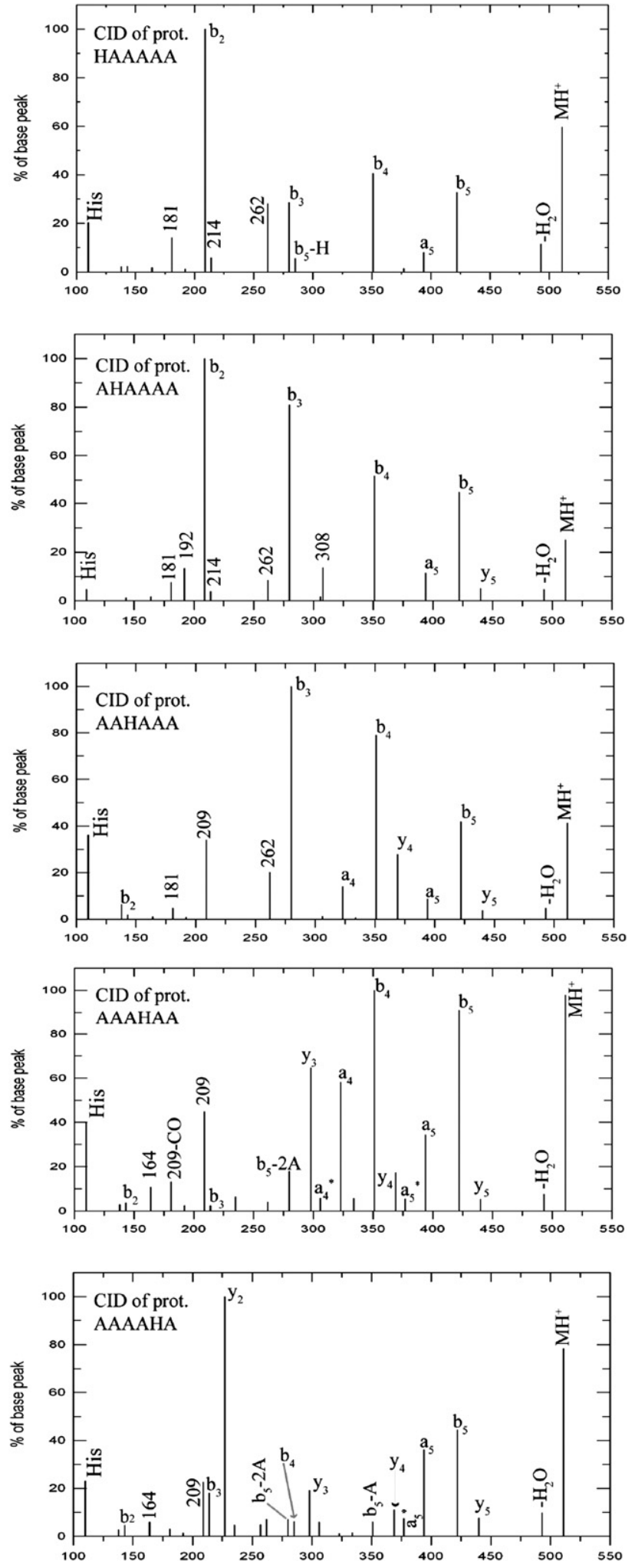

Figure 1. Product ion mass spectra (recorded at $22 \mathrm{eV}$ collision energy) of protonated HAAAAA, AHAAAA, AAHAAA, AAAHAA, and AAAAHA. 'His' denotes the His immonium ion at $m / z 110$.

at low or negligible abundances for protonated HAAAAA and AHAAAA, the CID spectra of protonated AAHAAA and AAAHAA feature $y$ ions with moderate intensities.
The $y_{2}$ ion is the base peak in the product ion mass spectrum of protonated AAAAHA.

The most abundant fragment ions always contain the basic His residue and the position of the His residue appears to determine the relative abundance of $b$ and $y$ fragments arising from the cleavage of a particular amide bond. This can be explained simply by considering the dissociation kinetics of the post-cleavage proton-bound dimers (PBDs) of the $\mathrm{N}$ - and C-terminal fragments formed by amide bond cleavages. In such PBDs the two fragments compete for the extra proton $[4,43,48]$ and the fragment with higher proton affinity is thus generally detected as the charged species in the mass spectrometer. The high basicity of the His side chain [49] means that the fragment containing His will preferentially keep the proton so be detected (i.e., it retains the charge). For example, AAAAHA can be cleaved at the $\mathrm{A}-\mathrm{H}$ amide bond to form $b_{4}$ and $y_{2}$ ions; the latter is more abundant since this contains the highly basic His residue.

Figure S1 (Supplementary Information), shows the breakdown graph for protonated AAHAAA. Apparently the $b_{5}, b_{4}, b_{3}$ and $y_{4}$ ions are all primary fragmentation products while $m / z 110,209$, and 262 are secondary fragmentation products. This indicates that the $\mathrm{A}-\mathrm{H}, \mathrm{H}-\mathrm{A}, \mathrm{A}(4)-\mathrm{A}(5)$, and $\mathrm{A}(5)-\mathrm{A}(6)$ amide bonds are cleaved with similar probabilities. This behavior is in contrast to the fragmentation behavior of protonated hexa-alanine [50], for which it is obvious that one has a significant proportion of sequential fragmentation resulting in the series $b_{5} \rightarrow b_{4} \rightarrow b_{3} \rightarrow b_{2}$. It is worth noting that the different behavior in the two systems is difficult to explain considering only the mobility of the ionizing proton [51]. The added proton is mobile in the hexaalanine case but for AAHAAA the added proton is probably more localized on the basic imidazole ring of the His residue [49]. This would indicate a more 'localized' primary fragmentation behavior for AAHAAA than for hexa-alanine. In contrast, for the latter case, the primary fragmentation occurs predominately from the species with the added proton on the C-terminal amide bond while in the former case the extra proton initiates competitive cleavage at several amide bonds upon collisional activation.

\section{Fragmentation of the $b_{3}$ Fragment of AAHAAA:} Formation of the His Iminium Ion

Figure 2 shows the breakdown graph for the $m / z 280 b_{3}$ ion of AAHAAA, where a major fragmentation product is the His iminium ion at $m / z 110$. Also observed are ion signals at $m / z 262$ (loss of $\mathrm{H}_{2} \mathrm{O}$ ) [52-54] and $m / z 209$. The formation of the His iminium ion is rationalized in Scheme 2, adapted from earlier work $[8,55,56]$. Loss of $\mathrm{CO}$ and cleavage of the $\mathrm{C}$-terminal amide bond lead to formation of a complex of a protonated oxazolone $\left(b_{2}\right.$ ion) and the His imine. In the complex, the extra proton transfers to the imine (presumably to the imidazole 


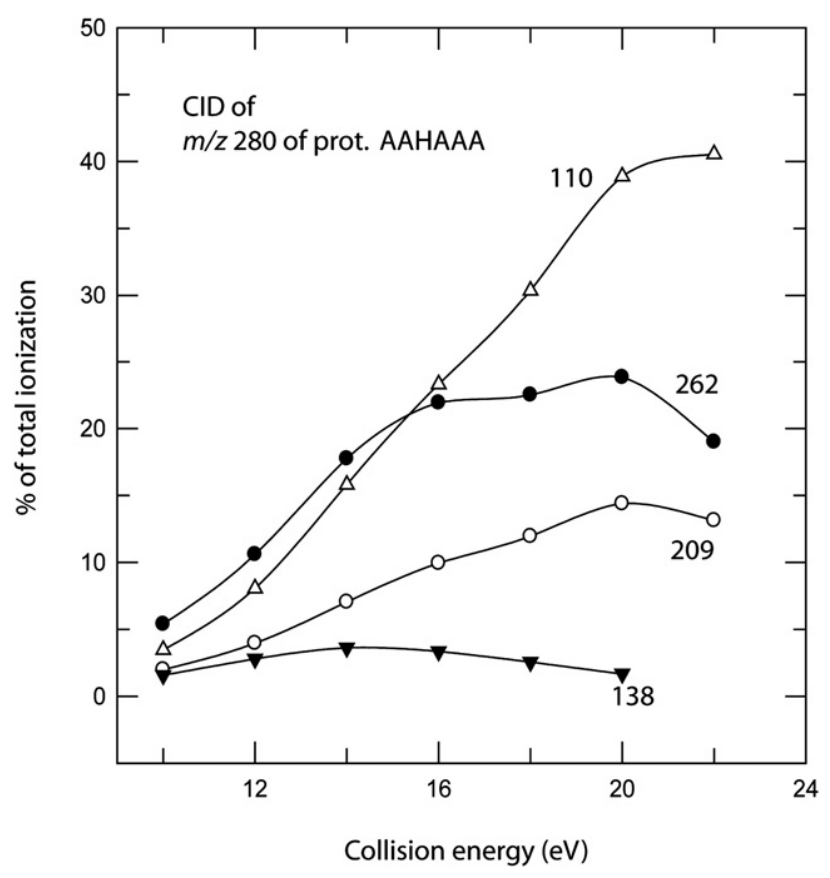

Figure 2. Breakdown graph for the $m / z 280$ fragment derived from protonated AAHAAA.

ring) as the proton affinity of the imine (calculated at $236.6 \mathrm{kcal} \mathrm{mol}^{-1}$ ), is much greater than that of the oxazolone $\left(222.3 \mathrm{kcal} \mathrm{mol}^{-1}\right.$ [43]). The $a_{3}$ ion is not observed in the product ion mass spectrum which is consistent with prior evidence that $a_{3}$ ions are unstable with respect to further fragmentation [32]. By rearrangement, the intermediate of Scheme 2 also can lead to formation of the $a_{n}{ }^{*}\left(a_{n}-\mathrm{NH}_{3}\right)$ ion [55-57]. Fragmentation of larger $a$ ions (which are observed) indicated formation of the respective $a_{n}{ }^{*}$ ion as well as the His iminium ion rather than elimination of the His imine to form the next lower $b_{n-1}$ ion (data not shown).

The $m / z 209$ product in Figure 2 corresponds to loss of an Ala residue from the $b_{3}$ ion and indicates the likely presence of a rearranged $b_{3}$ ion with an Ala residue at the $\mathrm{C}$-terminus $\left(\mathrm{AHA}_{\text {oxa }}\right.$ or $\left.\mathrm{HAA}_{\text {oxa }}\right)$. There are several possible pathways to this nominally rearranged $b_{3}$ ion. The first involves cyclization and rearrangement of the primary $\mathrm{AAH}_{\text {oxa }}$ sequence. This channel is highly unlikely to be active since all evidence [32] indicates that fully cyclic $b_{3}$ ions are not formed since they are much less stable than the oxazolone structure. The most likely pathway is by further fragmentation of rearranged $b_{4}$ and/or $b_{5}$ ions (see below). However, we cannot rule out the possibility of some formation of the $\mathrm{HAA}_{\text {oxa }}$ ion by further fragmentation of the $y_{4}$ ion (protonated HAAA). CID studies (results not shown) of the $y_{4}$ ion $(\mathrm{m} / \mathrm{z} 369)$ showed a very minor yield of a product at $\mathrm{m} / \mathrm{z}$ $280\left(\mathrm{HAA}_{\text {oxa }}\right)$, however the major products were direct formation of $m / z 209\left(\mathrm{HA}_{\text {oxa }}\right)$ as well as formation of the His iminium ion $(m / z 110)$. Nevertheless, this alternate

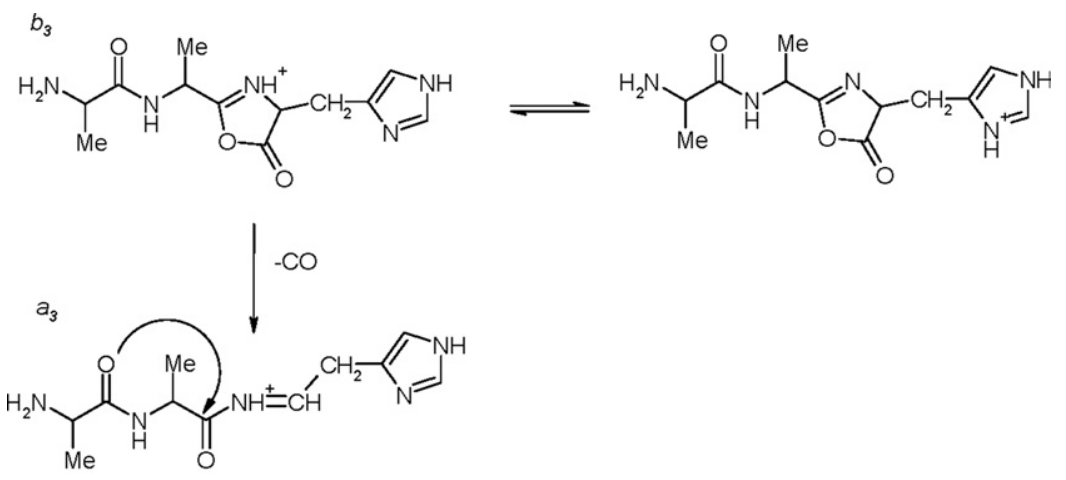<smiles>CI</smiles><smiles>CC1N=C([C@H](C)N)OC1=O</smiles><smiles>CC(N)C1=[NH+]C(C)C(=O)O1</smiles>

Scheme 2. Formation of the His immonium ion from the $\mathrm{AAH}_{\text {oxa }}$ isomer $b_{3}$ ion. 
structure for some of the $\mathrm{m} / \mathrm{z} 280$ product does not invalidate the conclusion reached above that $b_{n}$ ions with His at the C-terminus do not eliminate the His residue to form the next lower $b_{n}$ ion but rather tend to form the His iminium ion.

\section{Fragmentation of $b_{4}$ Ions}

Figure 3 shows, in bar graph form, the product ion mass spectra of the four $b_{4}$ ions $(\mathrm{m} / \mathrm{z} 351)$ studied. The spectra are not identical but are similar. These essentially involve different fragment ion intensities, with $\mathrm{m} / \mathrm{z} 280$ $\left(b_{4}-A\right)$ being the base peak in all cases, while none of the spectra features the $b_{4}-H(m / z 214)$ ion. These fragmentation characteristics indicate that the 'isomeric peptide' method that monitors elimination of the Ala and His residues from isomeric peptides to probe the extent of cyclization chemistry, is not a fully effective method in the present case since one of the key fragments is not present in the related spectra. This is an inherent limitation of the method as cyclization of the linear forms can still occur followed by fragmentation which fails to generate the conclusive $b_{4}-H$ peak. Therefore, this method does not provide uniform or unambiguous quantification. To obtain a more precise picture one needs to obtain additional information from theory (see below) or other experimental strategies such as IRMPD spectroscopy [33] or labeling [57, 58].

Nevertheless, the formation of the $b_{4}-A$ product in the fragmentation of the $b_{4}$ ion from protonated AAAHAA clearly must involve cyclization before fragmentation since this is a nondirect sequence ion in this case. Similarly, the formation of $m / z 209\left(b_{4}-2 A\right)$ in the product ion mass spectra of the $b_{4}$ ions derived from protonated AAHAAA and protonated AAAHAA are examples of cyclization and the formation of nondirect sequence ions. It should be explicitly understood however, that it is not possible to completely decouple the extent of cyclization and rearrangement of the $b_{4}$ ions from the cyclization and rearrangement of the $b_{5}$ ions which fragment to a considerable extent to form ions of $m / z 351$ (vide infra). Additionally, the $b_{4}$ ions also dissociate to form the $a_{4}{ }^{*}(\mathrm{~m} / \mathrm{z}$ 308) fragments in three of the four cases, although these are much less intense than the $b_{4}-A$ peak.

To understand the cyclization and reopening chemistry of the $b_{4}$ ions formed from the above peptides better, detailed DFT calculations were performed for the $\mathrm{HAAA}_{\text {oxa }}$, $\mathrm{AHAA}_{\text {oxa }}$, $\mathrm{AAHA}_{\text {oxa }}$, and $\mathrm{AAAH}_{\text {oxa }}$ linear $b_{4}$ isomers and protonated cyclo-(HAAA) (Figure 4). We have characterized the His side chain and backbone amide oxygen protonated structures for the macrocyclic isomers. For linear structures, protonation at the His side chain, the C-terminal oxazolone ring nitrogen, and the N-terminal amino nitrogen were considered. The energetically most favored species is the macrocyclic structure protonated at the His side-chain, while the most favorable open oxazolone structures also involve protonation at the His side chain and are 3.5 to $8.0 \mathrm{kcal}$ $\mathrm{mol}^{-1}$ higher in energy than the global minimum macrocyclic structure. In contrast to this finding, the calculated energetics for the $b_{4}$ ions with the YGGF [19] and AAAA [32] sequences show that the macrocyclic structures are less stable than the most favored linear structures. The amide oxygen protonated macrocyclic species of cyclo-(HAAA) are at 10.2 to $16.8 \mathrm{kcal} \mathrm{mol}^{-1}$ relative energy, while the oxazolone-N protonated open species are 10.9 to $13.7 \mathrm{kcal} \mathrm{mol}^{-1}$ higher in energy than the global minimum.

As illustrated in Scheme 1, the peptide precursors fragment first to form oxazolone-terminated structures, and these linear forms can then undergo either cyclization and/or direct oxazolone fragmentation. The relative energies of the cyclization TSs are at 25.2-30.3 $\mathrm{kcal} \mathrm{mol}^{-1}$ (Figure 4) relative to their respective His side chain protonated oxazolone isomers (HAAA oxa $\mathrm{AHAA}_{\text {oxa }}$, $\mathrm{AAHA}_{\text {oxa }}$, and $\mathrm{AAAH}_{\text {oxa }}$, respectively). These cyclization barriers are significantly higher than the barriers calculated previously for protonated cyclo(YAGFL) ( 17 kcal mol ${ }^{-1}$ [8] or cyclo-(GGGGG) (16.1 $\mathrm{kcal} \mathrm{mol}^{-1}$ [33] $b_{5}$ ions. This follows from the increasingly strained 12-membered macrocyclic ring $b_{4}$ ion transition structures and the presence of the basic His side chain from which the ionizing proton will need to have been mobilized, to enable cyclization to occur.

The open, oxazolone-terminated isomers are expected to undergo direct dissociation by elimination of $\mathrm{CO}$. This reaction usually requires $28-35 \mathrm{kcal} \mathrm{mol}^{-1}$ energy $[4,8,32,59,60]$ relative to the oxazolone minimum and forms the corresponding $a_{n}$ ion (a sample calculation on CO-loss from $\mathrm{AH}_{\text {oxa }}$ showed that loss of $\mathrm{CO}$ required $33.7 \mathrm{kcal} \mathrm{mol}^{-1}$ to initiate). This value is comparable to, but larger than, the cyclization barriers (25.2-30.3 kcal mol ${ }^{-1}$ ) calculated for the open HAAA $\mathrm{Hax}_{\text {, }}$ $\mathrm{AHAA}_{\text {oxa }}, \mathrm{AAHA}_{\text {oxa }}$, and $\mathrm{AAAH}_{\text {oxa }}$ isomers (Figure 4), indicating that cyclization is likely to compete directly with fragmentation by CO-loss. This is in sharp contrast to the energetics of the corresponding reactions of protonated cyclo-(YAGFL) [8] where the CO-loss barriers are $10-15 \mathrm{kcal} \mathrm{mol}^{-1}$ higher than the ring opening barriers, i.e., formation of cyclo-(YAGFL) is much more energetically facile than fragmentation by CO-loss. This suggests that cyclization is possible for the $b_{4}$ ions with the nominal $\mathrm{HAAA}_{\text {oxa }}$, $\mathrm{AHAA}_{\text {oxa }}$, $\mathrm{AAHA}_{\text {oxa }}$ and $\mathrm{AAAH}_{\text {oxa }}$ sequences, but also competitive with direct $b_{4}$ ion fragmentation via loss of $\mathrm{CO}$.

Once formed, the macrocyclic structure can undergo opening of the macro-ring (Scheme 1) to produce various open, oxazolone-terminated isomers. The relative energies of the ring opening TSs for protonated cyclo(HAAA) (Figure 4) are 30.6-35.9 kcal mol $\mathrm{k}^{-1}$ relative to the global minimum macrocyclic structure. These barriers are significantly higher than are the barriers calculated previously for protonated cyclo-(YAGFL) (22-27 $\mathrm{kcal} \mathrm{mol}^{-1}$ [8] or cyclo-(GGGGG) (25.0 kcal mol ${ }^{-1}$ [33]. The energetically most favored ring opening pathway leads to the $\mathrm{AAHA}_{\text {oxa }}$ linear form which is expected to 

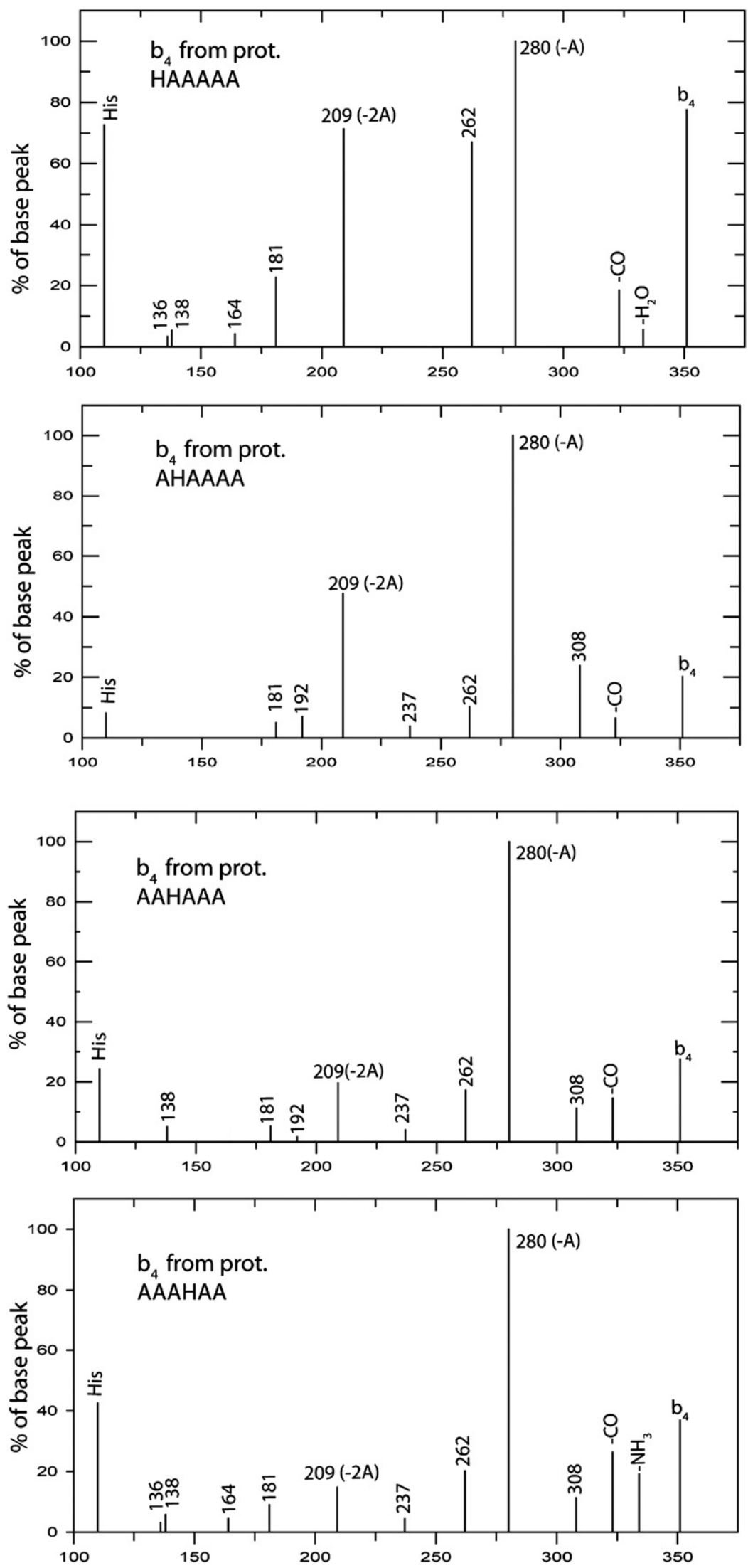

Figure 3. $\mathrm{MS}^{3}$ spectra (recorded at $22 \mathrm{eV}$ collision energy) of $b_{4}$ ions from protonated HAAAAA, AHAAAA, AAHAAA, and AAAHAA. 'His' denotes the His immonium ion at $m / z 110$. 


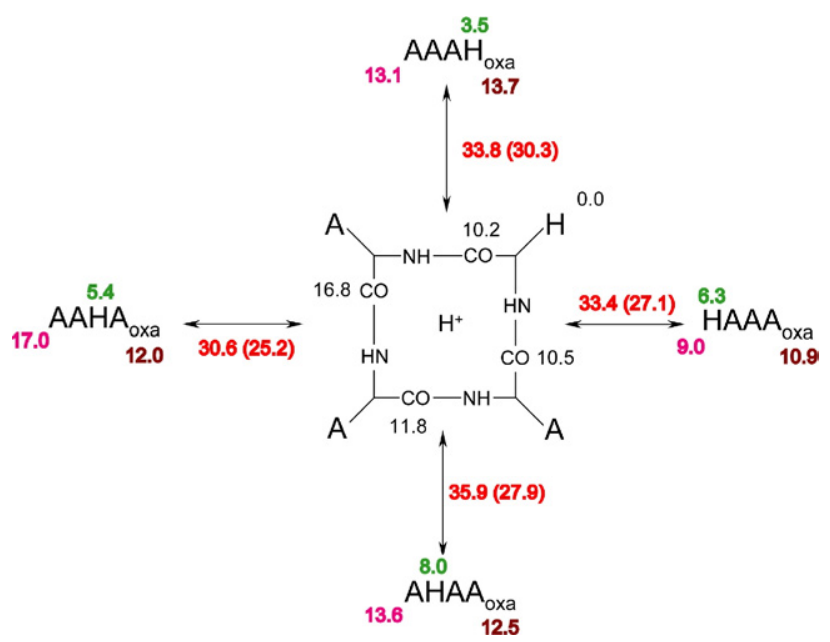

Figure 4. Relative energetics $\left(\mathrm{kcal} \mathrm{mol}^{-1}\right)$ of various species on the PES of protonated cyclo-(HAAA). The cyclo-peptide backbone is shown explicitly while amino acid side chains are denoted by $A$ (Ala) and $H$ (His), respectively. Relative energies of the amide oxygen protonation sites and TSs of the ring opening reactions of cyclo-(HAAA) are given in black and red, respectively. These reactions lead to the linear $b_{4}$ isomers $\mathrm{HAAA}_{\text {oxa }}, \mathrm{AHAA}_{\text {oxa }}$ $\mathrm{AAHA}_{\text {oxa }}$, and $\mathrm{AAAH}_{\text {oxal }}$, for which relative energies are presented for the $\mathrm{N}$-terminal amino (purple), C-terminal oxazolone (brown), and His side-chain (green) protonation sites. The cyclization barriers (given in parentheses) of the linear isomers can be calculated as the differences between the relative energies of the appropriate ring-opening TS and the corresponding linear isomer.

eliminate the C-terminal Ala residue. The corresponding $b_{4}-A$ ion is indeed the most abundant fragment in the CID spectra of the $b_{4}$ ions shown in Figure 3. The ring opening TSs to form $\mathrm{HAAA}_{\text {oxa }}$ and $\mathrm{AAAH}_{\text {oxa }}$ are equienergetic and less favored than the TS to form $\mathrm{AAHA}_{\text {oxa }}$ (Figure 4). Ring opening to HAAA oxa explains the formation of $b_{4}-2 A$ for the $b_{4}$ ion of protonated AAAHAA. Dissociation of the $\mathrm{AAAH}_{\text {oxa }}$ isomer can be rationalized based on the mechanisms discussed for the $b_{3}$ ion of protonated AAHAAA (see previous section and Scheme 2). After losing CO, a proton-bound dimer of the oxazolone composed of three Ala residues and the His imine is formed. The PA of the former (226 $\mathrm{kcal} \mathrm{mol}^{-1}$ [43] is lower than the PA of the imine (calculated at $236.6 \mathrm{kcal} \mathrm{mol}^{-1}$ ), explaining the moderately abundant His immonium ions in the last two panels of Figure 3.

The barriers to the CO-loss fragmentation channels in combination with the aforementioned cyclization barriers and the associated kinetics determine how similar the resulting spectra are. Our computational data on the cyclization and fragmentation reactions in addition to the observed fragmentation patterns suggest that the cyclization and scrambling chemistries are possible but competitive with direct fragmentation channels in a more pronounced manner than was observed previously for protonated YAGFL- $\mathrm{NH}_{2}$ and its isomers [8].

\section{Fragmentation of $b_{5}$ Ions}

The product ion mass spectra of the five $b_{5}$ ions $(\mathrm{m} / \mathrm{z}$ 422) are shown in bar-graph form in Figure 5 . The first observation is that the spectra are not identical, but share many common peaks. While the fragmentation patterns observed for the $b_{5}$ ions from protonated HAAAAA, AHAAAA, and AAHAAA are very similar
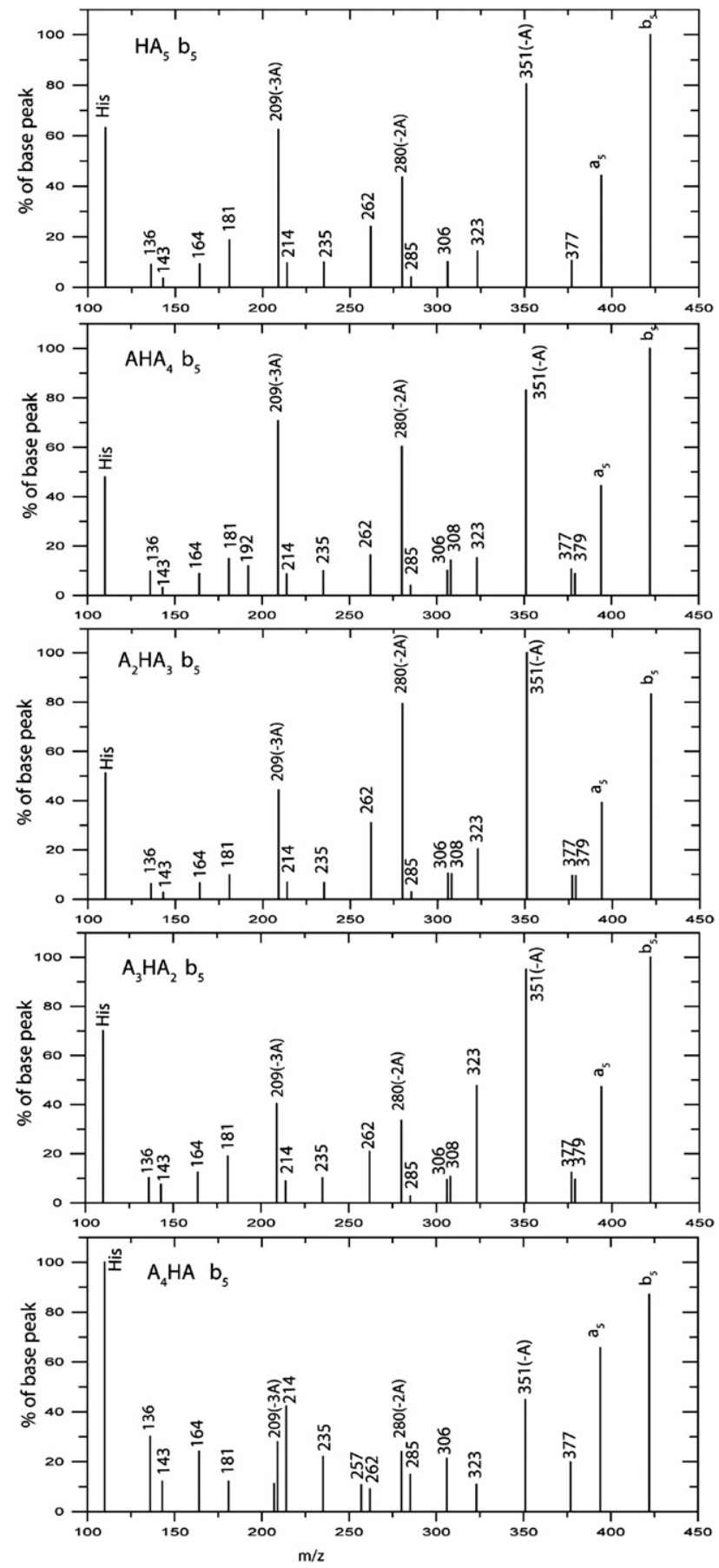

Figure 5. $\mathrm{MS}^{3}$ spectra (recorded at $26 \mathrm{eV}$ collision energy) of $b_{5}$ ions from protonated HAAAAA, AHAAAA, AAHAAA, AAAHAA, and AAAAHA. 'His' denotes the His immonium ion at $m / z 110$. 
to one another, the last two panels ( $b_{5}$ ions from protonated AAAHAA and AAAAHA) show spectra which are less similar, particularly in terms of relative intensities of peaks. This is in contrast to previous studies [8, 38, 41], where essentially identical product ion mass spectra were obtained for nominally isomeric $b_{5}$ ions from isomeric peptides with cyclically permuted structures. Those cases involved $b_{5}$ ions without strongly basic or acidic residues, and it was obvious that cyclization of the vast majority of the $b_{5}$ ion population to a common intermediate had occurred before fragmentation. For the present systems, containing the basic His residue, apparently isomerization, if it occurs, is not complete before fragmentation. Thus, more than one structure is likely to be involved in the fragmentation of these $b_{5}$ ions. This observation is in line with recent data from HDX experiments by Solouki and coworkers that suggest a mixture of linear and macrocyclic structures for the $b_{5}$ ions derived from protonated WHWLGL [42].

In the earlier studies [38, 41], loss of the tyrosine residue $(\mathrm{Y})$ placed at different positions in the starting peptide was used as an indicator of cyclization. In the present systems, the His residue placed at different positions is not lost to a significant extent from the $b_{5}$ ions except for the nominal AAAAH $b_{5}$ ion. In all other cases, the $b_{5}-H$ ion $(m / z 285)$ is at most $2 \%-3 \%$ of the base peak although further fragmentation to give low intensity ion signals at $\mathrm{m} / \mathrm{z} 214$ (oxazolone with the AAA sequence) and $m / z 143$ (oxazolone with the AA sequence) is observed. On the other hand, for the nominally AAAAH $b_{5}$ ion $b_{5}-H(m / z 285)$ is $15 \%$ of the base peak and the $m / z 214$ and 143 ion signals are also considerably more intense. Likely, this fragmentation occurs from the linear (i.e., not rearranged) $\mathrm{AAAAH}_{\text {oxa }}$ structure. In the discussions above of the fragmentation of the nominal AAH $b_{3}$ and AAAH $b_{4}$ ions, it was pointed out that the His imine has a much higher proton affinity $\left(236.6 \mathrm{kcal} \mathrm{mol}^{-1}\right)$ than the AA or AAA oxazolones (223.3 and $226 \mathrm{kcal} \mathrm{mol}^{-1}$, respectively) and, thus, that the formation of the protonated oxazolones was not to be expected in these cases. For the AAAAH $b_{5}$ system the AAAA oxazolone has a proton affinity of $232.6 \mathrm{kcal} \mathrm{mol}^{-1}$ [43] making formation of the protonated oxazolone $\left(\mathrm{AAAA}_{\text {oxa }}, \mathrm{m} / \mathrm{z} 285\right)$ much more competitive. This structure once formed can fragment consecutively to produce the $m / z 214\left(\right.$ AAA $\left._{\text {oxa }}\right)$ and 143 $\left(\mathrm{AA}_{\text {oxa }}\right)$ peaks.

The limited abundance or complete lack of the $b_{5}-H$ $(m / z 285)$ signal indicates that the 'isomeric peptide' method that is based on observing elimination of both the Ala and His residues from isomeric peptides, is not fully effective in the present case since one of the key fragments is not present in the related spectra. This can be rationalized by assuming limited cyclization of the investigated $b_{5}$ ions or as an inherent limitation of the method which hinders quantification of the branching ratio of cyclization and direct fragmentation pathways if both are present. To obtain a more precise picture we applied theory to gain additional information of the related energetics (see below).

Apart from the low intensity ion signals for $b_{5}-H(m / z$ 285), there is no further CID evidence for cyclization of the $b_{5}$ ions derived from $\mathrm{HA}_{5}$ or $\mathrm{AHA}_{4}$; in both cases one observes sequential loss of alanine residues to form, eventually, the nominally $b_{2}$ ion at $\mathrm{m} / z 209$. In contrast, the experimental spectra of the remaining $b_{5}$ ions show clear evidence for at least partial cyclization and scrambling according to Scheme 1. In the absence of such cyclization/reopening reactions followed by fragmentation, one would not expect to observe loss of three alanine residues for the $b_{5}$ ions derived from protonated AAHAAA, the loss of two and three alanine residues from the $b_{5}$ ion derived from protonated AAAHAA nor the loss of one, two and three alanine residues from the $b_{5}$ ion derived from protonated AAAAHA. These fragment ions correspond to nondirect sequence ions [7, 8]. Figure S2 (Supporting Material) shows the breakdown graph for the $b_{5}$ ion derived from protonated AAHAAA (only the major ions are shown). The sequential loss of alanine residues (as $\mathrm{CH}_{3} \mathrm{CH}=\mathrm{NH}+\mathrm{CO}$ ) from the $b_{5}$ ion is clearly evident.

Our computed energetics for the open and macrocyclic $b_{5}$ structures are summarized in Figure 6. Again the most stable structure is the macrocyclic species protonated at the His side chain, although the macrocyclic structures protonated at amide oxygens near the His residue are only slightly higher in energy (3.7 and 4.3 $\mathrm{kcal} \mathrm{mol}^{-1}$ relative energies, respectively). All linear

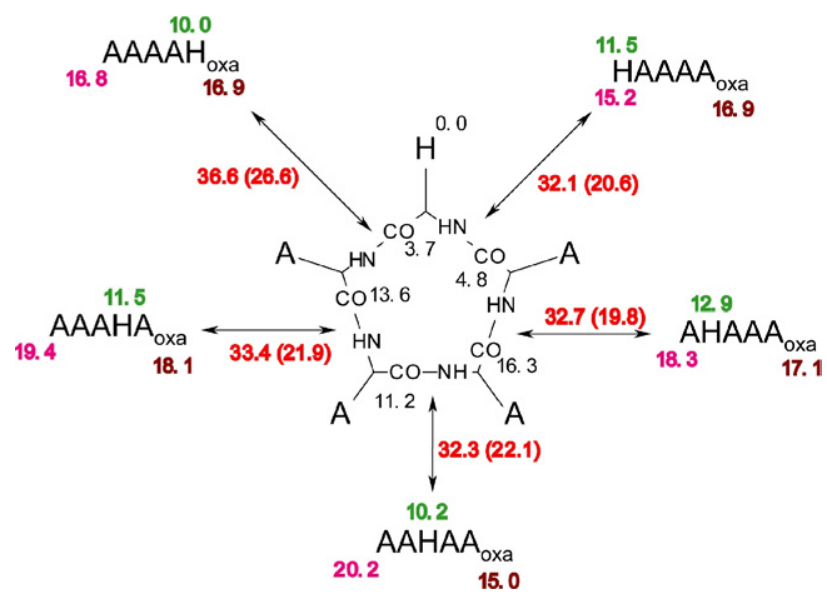

Figure 6. Relative energetics $\left(\mathrm{kcal} \mathrm{mol}^{-1}\right)$ of various species on the PES of protonated cyclo-(HAAAA). The cyclo-peptide backbone is shown explicitly while amino acid side chains are denoted by $A$ (Ala) and $H$ (His), respectively. Relative energies of the amide oxygen protonation sites and TSs of the ring opening reactions of protonated cyclo-(HAAAA) are given in black and red, respectively. The relative energies of the linear $b_{5}$ isomers like HAAAA $_{\text {oxa }}$, AHAAA $_{\text {oxa }}$, AAHAA $_{\text {oxa }}$, AAAHA $_{\text {oxa }}$, and AAAAH $_{\text {oxa }}$ are presented in purple, brown, and green for the N-terminal amino, C-terminal oxazolone, and His side-chain protonation sites, respectively. The cyclization barriers (given in parentheses) of the linear isomers can be calculated as the differences between the relative energies of the appropriate ring-opening TS and the corresponding linear isomer. 
structures are energetically less favored with the His side chain protonated oxazolones being 10.0-12.9 kcal $\mathrm{mol}^{-1}$ higher in energy than the most stable macrocyclic structure. This is a larger difference than observed for the $b_{4}$ system (3.5-8.0 kcal mol${ }^{-1}$, Figure 4) and presumably reflects the increased stability of the 15membered macrocyclic ring $\left(b_{5}\right)$ compared with the 12-membered $\left(b_{4}\right)$ macrocyclic ring.

The reaction pattern of Scheme $\mathbf{1}$ indicates that the open, oxazolone-terminated forms are generated directly from the parent peptide and these then undergo cyclization to form the macrocyclic structure. The cyclization barriers of the open forms are in the 19.8-26.6 $\mathrm{kcal} \mathrm{mol}^{-1}$ range relative to their corresponding oxazolone forms. These threshold energies are lower than the corresponding cyclization threshold energies computed for the $b_{4}$ system (25.2-30.3 kcal mol${ }^{-1}$, Figure 4). This difference in energy can be explained by the increased stability of the larger macrocyclic ring transition structure formed for $b_{5}$ compared with the strained 12 -membered $b_{4}$ macrocyclic transition structures. The $b_{5}$ cyclization threshold energies are $\sim 5-12 \mathrm{kcal} \mathrm{mol}^{-1}$ lower than is normally necessary for CO-loss indicating that there should be little energetic impediment to these cyclization reactions occurring. The lowest cyclization barriers are computed for the HAAAA oxa AHAAA $_{\text {oxa }}$ and $\mathrm{AAHAA}_{\text {oxa }}$ sequences for which very similar fragmentation patterns are observed. These can be mostly explained for the first two by assuming only direct fragmentation but this is clearly not the case for the last sequence. The largest cyclization barrier is for the AAAAH $_{\text {oxa }}, b_{5}$ sequence (26.6 kcal mol ${ }^{-1}$, Figure 6) where it appears from the experimental results that fragmentation is most different from that observed for the first three sequences HAAAA $_{\text {oxa }}, \mathrm{AHAAA}_{\text {oxa, }}$ AAHAA $_{\text {oxa }}$ ), which are most similar to each other. This $b_{5}$ ion shows the largest $b_{5}-H$ peak indicating that a larger proportion of this ion fragments directly from the $\mathrm{AAAAH}_{\text {oxa }}$ form than is the case for the other sequences. This production of direct sequence ions is logical as the CO-loss fragmentation reaction $(\sim 28-35$ $\left.\mathrm{kcal} \mathrm{mol}^{-1}\right)$ is likely to compete with the cyclization reaction (threshold energy at $26.6 \mathrm{kcal} \mathrm{mol}^{-1}$, Figure 6), which is significantly more energetically demanding $\left(4.7 \mathrm{kcal} \mathrm{mol}^{-1}\right)$ than the cyclization reactions of the other $b_{5}$ analogues.

Nevertheless, the experimental spectra clearly indicate that similarly to the $b_{4}$ case the cyclization and the related scrambling chemistry are active for $b_{5}$ ions but competition with direct fragmentation channels is pronounced, especially for the $b_{5}$ ions formed from protonated AAAAHA.

\section{Conclusions}

In earlier studies of isomeric $b_{5}$ ions of peptides with cyclically permuted sequences, near identical product ion mass spectra were obtained indicating almost complete cyclization of the permuted oxazolone $b_{5}$ ions to a common intermediate before fragmentation $[8,38,39$, 41]. This generated frequent formation of nondirect sequence ions making $\mathrm{MS}^{3}$ studies involving these $b$ ions ambiguous in deriving sequence information as well as hindered traditional $\mathrm{MS}^{2}$ sequencing. These studies involved peptides which did not contain strongly basic or acidic residues. In the present study, involving $b_{5}$ ions containing the basic His residue, experimental and theoretical evidence is obtained for cyclization, particularly when the His residue is near the C-terminus of the nominal $b_{5}$ ion sequence. When the residue was near the $\mathrm{N}$-terminus no clear experimental evidence of cyclization was recorded in the dissociation patterns, despite theoretical calculations indicating that such processes should be energetically facile. Scrambling was also detected in the fragmentation of the $b_{4}$ ions, despite the more similar energies of the fragmentation and cyclization reactions. In fact, the cyclization/reopening chemistry is more obviously active in the experimental data of the $b_{4}$ ions than for $b_{5}$ fragments. However, three caveats should be explicitly understood when considering these peptides and their reactions: (1) the presence of multiple alanines complicates the assignment of 'scrambled' peaks due to peak degeneracy, (2) the 'isomeric peptide' method is not expected to provide entirely objective qualitative answers if cyclization of the studied $b$ ions is not complete, and (3) it is possible that some of the fragmented $b_{4}$ ions resulted from initial fragmentation of $b_{5}$ ions and that this could have occurred after sequence scrambling (as the $b_{4}$ peaks are isobaric, mass spectrometry would not be able to distinguish them, unlike for the systems containing fve differing residues (e.g., YAGFL).

\section{Acknowledgments}

A.G.H. is indebted to the Natural Sciences and Engineering Research Council (Canada) for continued financial support. B.J.B. thanks the DKFZ for a guest scientist fellowship. B.P. is grateful to the Deutsche Forschungsgemeinschaft for a Heisenberg fellowship.

\section{Appendix A Supplementary Material}

Supplementary material associated with this article may be found in the online version at doi:10.1016/ j.jasms.2010.05.006.

\section{References}

1. Larsen, M. R.; Roepstorff, P. Mass Spectrometric Identification of Proteins and Characterization of their Post-Translational Modifications. Fresenius J. Anal. Chem. 2000, 366, 677-690.

2. Aebersold, R.; Goodlett, D. R. Mass Spectrometry in Proteomics. Chem. Rev. 2001, 101, 269-295.

3. Medzihradszky, K. Peptide Sequence Analysis. Methods Enzymol. 2005, 402, 209-244.

4. Paizs, B.; Suhai, S. Fragmentation Pathways of Protonated Peptides. Mass Spectrom. Rev. 2005, 24, 508-548.

5. Roepstorff, P.; Fohlmann, J. Proposals for a Common Nomenclature for Sequence Ions in Mass Spectra of Peptides. Biomed. Mass Spectrom. 1984, 11, 601 . 
6. Biemann, K. Contributions of Mass Spectrometry to Peptide and Protein Structure. Biomed. Env. Mass Spectrom. 1988, 16, 99-111.

7. Harrison, A. G.; Young, A. B.; Bleiholder, C.; Suhai, S.; Paizs, B. Scrambling of Sequence Information in Collision-Induced Dissociation of Peptides. J. Am. Chem. Soc. 2006, 128, 10364-10365.

8. Bleiholder, C.; Osburn, S.; Williams, T. D.; Suhai, S.; Van Stipdonk, M.; Harrison, A. G.; Paizs, B. Sequence-Scrambling Pathways of Protonated Peptides. J. Am. Chem. Soc. 2008, 130, 17774-17789.

9. Mueller, D. R.; Eckersley, M.; Richter, W. Hydrogen Transfer Reactions in the Formation of " $\mathrm{Y}+2$ " Sequence Ions from Protonated Peptides. Org. Mass Spectrom. 1988, 23, 217-222.

10. Cordero, M. M.; Houser, J. J.; Wesdemiotis, C. The Neutral Products Formed During Backbone Cleavage of Protonated Peptides in Tandem Mass Spectrometry. Anal. Chem. 1993, 65, 1594-1601.

11. Harrison, A. G. To b or not to $\mathrm{b}$. The Ongoing Saga of Peptide $b$ Ions. Mass Spectrom. Rev. 2009, 28, 640-654.

12. Yalcin, T.; Khouw, C.; Csizmadia, I. G.; Peterson, M. R.; Harrison, A. G. Why are $b$ Ions Stable Species in Peptide Mass Spectra? J. Am. Soc. Mass Spectrom. 1995, 6, 1165-1174.

13. Yalcin, T.; Csizmadia, I. G.; Peterson, M. R.; Harrison, A. G. The Structures and Fragmentation of $\mathrm{B}_{n}(n \geq 3)$ Ions in Peptide Mass Spectra. J. Am. Soc. Mass Spectrom. 1996, 7, 233-242.

14. Nold, M. J.; Wesdemiotis, C.; Yalcin, T.; Harrison, A. G. Amide Bond Dissociation in Protonated Peptides. Structures of the N-terminal Ionic and Neutral Fragments. Int. J. Mass Spectrom. Ion Processes 1997, 164, 137-153.

15. Paizs, B.; Lendvay, G.; Vékey, K.; Suhai, S. Formation of $b_{2}^{+}$Ions from Protonated Peptides. Rapid Commun. Mass Spectrom. 1999, 13, 523-533.

16. Harrison, A. G.; Csizmadia, I. G.; Tang, T.-H. Structures and Fragmentation of $b_{2}$ Ions in Peptide Mass Spectra. J. Am. Soc. Mass Spectrom. 2000, $11,427-436$.

17. Rodriquez, C. F.; Shoeib, T.; Chu, I. K.; Siu, K. W. M.; Hopkinson, A. C. Comparison Between Protonation, Lithiation and Argentination of 5-Oxazolones. A Study of a Key Intermediate in Gas-Phase Peptide Sequencing. J. Phys. Chem. A 2000, 104, 5335-5342.

18. Polfer, N. C.; Oomens, J.; Suhai, S.; Paizs, B. Spectroscopic and Theoretical Evidence for Oxazolone Ring Formation in Collision-Induced Dissociation of Peptides. J. Am. Chem. Soc. 2005, 127, 17154-17155.

19. Polfer, N. C.; Oomens, J.; Suhai, S.; Paizs, B. Infrared Spectroscopy and Theoretical Studies on Gas-Phase Protonated Leu-Enkephalin and Its Fragments: Direct Experimental Evidence for the Mobile Proton. J. Am. Chem. Soc. 2007, 129, 5887-5897.

20. Yoon, S. H.; Chamot-Rooke, J.; Perkins, B. R.; Hilderbrand, A. E.; Poutsma, J. C.; Wysocki, V. H. IRMPD. Spectroscopy Shows That AGG Forms an Oxazolone $\mathrm{b}_{2}^{+}$Ion. J. Am. Chem. Soc. 2008, 130, 17644-17645.

21. Oomens, J.; Young, S.; Molesworth, S.; Van Stipdonk, M. Spectroscopic Evidence for an Oxazolone Structure of the $b_{2}$ Ion from Protonated Tri-Alanine. J. Am. Soc. Mass Spectrom. 2009, 20, 334-339.

22. Bythell, B. J.; Erlekam, U.; Paizs, B.; Maitre, P. Infrared Spectroscopy of Fragments Derived from Tryptic Peptides. Chem. Phys. Chem. 2009, 10, 883-885.

23. Bythell, B. J.; Somogyi, Á.; Paizs, B. What is the Structure of $b_{2}$ Ions Generated from Doubly Protonated Tryptic Peptides? J. Am. Soc. Mass Spectrom. 2009, 20, 618-624.

24. Yalcin, T.; Harrison, A. G. Ion Chemistry of Protonated Lysine Derivatives. J. Mass Spectrom. 1996, 31, 1237-1243.

25. Tu, Y.-P.; Harrison, A. G. The $b_{1}$ Ion Derived from Methionine is a Stable Species. Rapid Commun. Mass Spectrom. 1998, 12, 849-851.

26. Yu, W.; Vath, J. E.; Huberty, M. C.; Martin, S. A. Identification of the Facile Gas-phase Cleavage of the Asp-Pro and Asp-Xxx Peptide Bonds in Matrix-assisted Laser Desorption Time-of-flight Mass Spectrometry. Anal. Chem. 1993, 65, 3015-3023.

27. Farrugia, J. M.; Taverner, T.; O'Hair, R. A. J. Side-Chain Involvement in the Fragmentation Reactions of Protonated Methyl Esters of Histidine and its Peptides. Int. J. Mass Spectrom. 2001, 209, 99-112.

28. Farrugia, J. M.; O'Hair, R. A. J.; Reid, G. A. Do All b Ions Have Oxazolone Structures? Multistage Mass Spectrometry and Ab Initio Studies on Protonated N-Acyl Amino Acid Methyl Ester Model Systems. Int. J. Mass Spectrom. 2001, 210/211, 71-87.

29. Csonka, I. P.; Paizs, B.; Lendvay, G.; Suhai, S. Proton Mobility and Main Fragmentation Pathways of Protonated Lysylglycine. Rapid Commun. Mass Spectrom. 2001, 15, 1457-1472.

30. Knapp-Mohammady, M.; Young, A. B.; Paizs, B.; Harrison, A. G. Fragmentation of Doubly-Protonated Pro-His-Xaa Tripeptides: Formation of $b_{2}^{2+}$ Ions. I. Am. Soc. Mass Spectrom. 2009, 20, 2135-2143.

31. Bythell, B. J.; Csonka, I. P.; Suhai, S.; Barofsky, D. F.; Paizs, B. Gas-Phase Structure and Fragmentation Pathways of Singly Protonated Peptides with N-Terminal Arginine J. Phys. Chem. A, unpublished (submitted).

32. Allen, J. M.; Racine, A. H.; Berman, A. M.; Johnson, J. S.; Bythell, B. J.; Paizs, B.; Glish, G. L. Why are $\mathrm{a}_{3}$ Ions Rarely Observed? J. Am. Soc. Mass Spectrom. 2008, 19, 1764-1770.

33. Erlekam, U.; Bythell, B. J.; Scuderi, D.; Van Stipdonk, M.; Paizs, B.; Maitre, P. Infrared Spectroscopy of Fragments of Protonated Peptides. Direct Evidence for Macrocyclic Structure of $b_{5}$ Ions. J. Am. Chem. Soc. 2009, 131, 11503-11508.

34. Tang, X.-J.; Thibault, P.; Boyd, R. K. Fragmentation of MultiplyProtonated Peptides and Implications for Sequencing by Tandem Mass Spectrometry with Low-Energy Collision-Induced Dissociation. Anal. Chem. 1993, 65, 2824-2834.
35. Tang, X.-J.; Boyd, R. K. Rearrangement of Doubly-Charged Acylium Ions from Lysyl and Ornithyl Peptides. Rapid Commun. Mass Spectrom. $1994,8,678-686$

36. Yague, J.; Paradela, A.; Ramos, M.; Ogueta, S.; Marina, A.; Barabona, F.; Lopez de Castro, J. A.; Vazquez, J. Peptide Rearrangement During Ion Trap Fragmentation: Added Complexity to MS/MS Spectra. Anal. Chem. 2003, 75, 1524-1535.

37. Mouls, L.; Aubagnac, J. L.; Enjalbal, C. Low Energy Peptide Fragmentations in an ESI-Q-TOF Type Mass Spectrometer. J. Proteome Res. 2007, $6,1378-1391$.

38. Harrison, A. G. Sequence Scrambling Through Cyclization of $b_{5}$ Ions. J. Am. Soc. Mass Spectrom. 2008, 19, 1776-1780.

39. Molesworth, S.; Osburn, S.; Van Stipdonk, M. Influence of Size on Apparent Scrambling of Sequence During CID of b-Type Ions. J. Am. Soc. Mass Spectrom. 2009, 20, 2174-2181.

40. Riba-Garcia, I.; Giles, K.; Bateman, R. H.; Gaskell, S. J. Evidence for Structural Variants of $a$ - and $b$-Type Peptide Fragment Ions Using Combined Ion Mobility/Mass Spectrometry. J. Am. Soc. Mass Spectrom. 2008, 19, 609-613.

41. Harrison, A. G. Cyclization of Peptide $b_{9}$ Ions. J. Am. Soc. Mass Spectrom 2009, 20, 2248-2253.

42. Fattahi, A.; Zekavat, B.; Solouki, T. H/D Exchange Kinetics: Experimental Evidence for Formation of Different $b$ Fragment Ion Conformers/ Isomers During the Gas-Phase Peptide Sequencing. J. Am. Soc. Mass Spectrom. 2010, 21, 358-369.

43. Paizs, B.; Suhai, S. Towards Understanding the Tandem Mass Spectra of Protonated Oligopeptides. 1: Mechanism of Amide Bond Cleavage. J. Am. Soc. Mass Spectrom. 2004, 15, 103-113.

44. Wyttenbach, T.; Paizs, B.; Barran, P.; Breci, L. A.; Liu, D.; Suhai, S. Wysocki, V. H.; Bowers, M. T. The Effect of the Initial Water of Hydration on the Energetics, Structures, and H/D-exchange Mechanism of a Family of Pentapeptides: An Experimental and Theoretical Study. J. Am. Chem. Soc. 2003, 123, 13768-13775.

45. Case, D. A.; Pearlman, D. A.; Caldwell, J. W.; Cheatham T. E. III; Ross, W. S.; Simmerling, C. L.; Darden, T. A.; Merz, K., M.; Stanton, R. V.; Cheng, A. L.; Vincent, J. J.; Crowley, M.; Tsui, V.; Radmer, R. J.; Duan, Y.; Pitera, J.; Massova, I. G.; Seibel, G. L.; Singh, U. C.; Weiner, P. K.; Kollmann, P. A. AMBER 99; University of California: San Francisco, 1999.

46. Frisch, M. J.; Trucks, G. W.; Schlegel, H. B.; Scuseria, G. E.; Robb, M. A. Cheeseman, J. R.; Montgomery, J. A. Jr.; Vreven, T.; Kudin, K. N.; Burant, J. C.; Millam, J. M.; Iyengar, S. S.; Tomasi, J.; Barone, V.; Mennucci, B.; Cossi, M.; Scalmani, G.; Rega, N.; Petersson, G. A. Nakatsuji, H.; Hada, M.; Ehara, M.; Toyota, K.; Fukuda, R.; Hasegawa, J.; Ishida, M.; Nakajima, T.; Honda, Y.; Kitao, O.; Nakai, H.; Klene, M.; Li, X.; Knox, J. E.; Hratchian, H. P.; Cross, J. B.; Bakken, V.; Adamo, C. Jaramillo, J.; Gomperts, R.; Stratmann, R. E.; Yazyev, O.; Austin, A. J.; Cammi, R.; Pomelli, C.; Ochterski, J. W.; Ayala, P. Y.; Morokuma, K.; Voth, G. A.; Salvador, P.; Dannenberg, J. J.; Zakrzewski, V. G.; Dapprich, S.; Daniels, A. D.; Strain, M. C.; Farkas, O.; Malick, D. K.; Rabuck, A. D.; Raghavachari, K.; Foresman, J. B.; Ortiz, J. V.; Cui, Q.; Baboul, A. G.; Clifford, S.; Cioslowski, J.; Stefanov, B. B.; Liu, G.; Liashenko, A. Piskorz, P.; Komaromi, I.; Martin, R. L.; Fox, D. J.; Keith, T.; Al-Laham, M. A.; Peng, C. Y.; Nanayakkara, A.; Challacombe, M.; Gill, P. M. W.; Johnson, B.; Chen, W.; Wong, M. W.; Gonzalez, C.; Pople, J. A. Gaussian C2; Gaussian Inc.: Wallingford CT, 2004

47. Tsaprailis, G.; Nair, H.; Zhong, W.; Kuppannan, K.; Futrell, J. H. Wysocki, V. H. A Mechanistic Investigation of the Enhanced Cleavage at Histidine in the Gas-Phase Dissociation of protonated Peptides. Anal. Chem. 2004, 76, 2083-2094.

48. Paizs, B.; Suhai, S. Towards Understanding Some Ion Intensity Relationships for the Tandem Mass Spectra of Protonated Peptides. Rapid Commun. Mass Spectrom. 2002, 16, 1699-1702.

49. Bleiholder, C.; Suhai, S.; B. Paizs. Revising the Proton Affinity Scale of the Naturally Occurring $\alpha$-Amino Acids. J. Am. Soc. Mass Spectrom. 2006 $17,1275-1281$

50. Harrison, A. G.; Young, A. B. Fragmentation of Protonated OligoAlanines: Amide Bond Cleavage and Beyond. J. Am. Soc. Mass Spectrom. 2004, 15, 1810-1819.

51. Wysocki, V. H.; Tsaprailis, G.; Smith, L. L.; Breci, L. A. CommentaryMobile and Localized Protons: A Framework for Understanding Peptide Dissociation. J. Mass Spectrom. 2000, 35, 1399-1406.

52. Ballard, K. D.; Gaskell, S. J. Dehydration of Peptide $[\mathrm{M}+\mathrm{H}]^{+}$Ions in the Gas Phase. J. Am. Soc. Mass Spectrom. 1993, 4, 477-481.

53. Reid, G. E.; Simpson, R. J.; O'Hair, R. A. J. Probing the Fragmentation Reactions of Protonated Glycine Oligomers Via Multistage Mass Spectrometry and Gas Phase Ion Molecule Hydrogen/Deuterium Exchange Int. J. Mass Spectrom. 1999, 190/191, 209-230.

54. Bythell, B. J.; Dain, R. P.; Curtice, S. S.; Oomens, J.; Steill, J. D.; Groenewold G. S.; Paizs, B.; Van Stipdonk, M. J. Structure of $\left[\mathrm{M}+\mathrm{H}-\mathrm{H}_{2} \mathrm{O}\right]^{+}$from Protonated Tetraglycine Revealed by Tandem Mass Spectrometry and IRMPD Spectroscopy J. Phys. Chem. A 2010, 114, 5076-5082.

55. Cooper, T.; Talaty, E.; Grove, J.; Van Stipdonk, M.; Suhai, S.; Paizs, B. Isotope Labeling and Theoretical Study of the Formation of $\mathrm{a}_{3}{ }^{*}$ Ions from Protonated Tetraglycine. J. Am. Soc. Mass Spectrom. 2006, 17, 1654-1664.

56. Harrison, A. G. Fragmentation Reactions of Some Peptide $b_{3}$ Ions: An Energy-Resolved Study. Rapid Commun. Mass Spectrom. 2009, 23, 1298 1302.

57. Bythell, B. J.; Molesworth, S.; Osburn, S.; Cooper, T.; Paizs, B.; Van Stipdonk, M. Structure and Reactivity of $a_{n}$ and $a_{n}{ }^{*}$ Peptide Fragments 
Investigated Using Isotope Labeling, Tandem Mass Spectrometry and Density Functional Theory Calculations. J. Am. Soc. Mass Spectrom. 2008, $19,1788-1798$

58. Chen, X.; Yu, L.; Steill, J. D.; Oomens, J.; Polfer, N. C. Effect of Peptide Fragment Size on the Propensity of Cyclization in Collision-Induced Dissociation: Oligoglycine $b_{2}-b_{8}$. J. Am. Chem. Soc., 2009, 131, 18272-18282.
59. Paizs, B.; Szlávik, Z.; Lendvay, G.; Vékey, K.; Suhai, S. Formation of $\mathrm{a}_{2}^{+}$ Ions of Protonated Peptides. An Ab Initio Study. Rapid Commun. Mass Spectrom. 2000, 14, 746-755.

60. El Aribi, H.; Orlova, G.; Rodriquez, C. F.; Almeida, D. R. P.; Hopkinson, A. C.; Siu, K. W. M. Fragmentation Mechanisms of Product Ions from Protonated Tripeptides. J. Phys. Chem. B 2004, 108, 18743-18749. 